\title{
A comparative evaluation of efficacy of a reciprocating system for gutta-percha removal with or without a solvent
}

\author{
Nancy Kudsi Carvalho, ${ }^{1}$ Gustavo Ribeiro Alvares, ${ }^{1}$ Luciana Moura Sassone, ${ }^{1}$ Renato Liess Krebs, ${ }^{1}$ Tauby de Souza Coutinho-Filho, ${ }^{1}$ Emmanuel João Nogueira \\ Leal da Silva ${ }^{1}$ \\ 'Department of Endodontics, Rio de Janeiro State University (UERJ), Rio de Janeiro, RJ, Brazil \\ - Conflicts of interest: none declared.
}

\section{Abstract}

Objective: to evaluate the efficacy of Reciproc System, with or without solvent for endodontic filling removal from oval shaped root canals. The time required for gutta-percha removal and the instrument fracture were also evaluated. Material and Methods: forty straight single-rooted premolars were prepared up to a size 30 and filled with gutta-percha and sealer, then randomly assigned to two retreatment groups $(n=20)$, treated with Reciproc System with or without chloroform (RS+C and RS). For all roots, procedural errors, time of retreatment and apically extruded material were recorded. After retreatment, roots were split longitudinally and then photographed. All images were evaluated with Image Tool software to calculate the percentage of residual material. Kolmogorov Smirnov and $t$ tests were used to determine significant differences at $P<.05$. Results: no treatment completely removed the root filling material from the root canals. Analysis of the total area did not reveal statistical differences between the two groups $(P>.05)$. Both groups also showed similar results in all tested thirds, with no statistical differences $(P>.05)$. RS without solvent was faster in filling material removal than $\mathrm{RS}+\mathrm{C}(P<.05)$. For both groups, none of the instruments showed intracanal fracture or visible signs of plastic deformation. Conclusion: taken together, our results demonstrated that Reciproc System used without solvent required less time to remove the same amount of root filling material than Reciproc System with solvent. However, regardless of solvent use, the same cleaning quality was obtained.

Keywords: Endodontic retreatment; Reciprocating; Instrumentation; Solvents.

\section{Introduction}

$\mathbf{W}$ hen nonsurgical retreatment is indicated, efficient removal of the filling material from the root canal system is essential to ensure a favorable outcome. ${ }^{1,2}$ Numerous techniques have been proposed for removing root filling materials, including stainless steel hand files, ${ }^{3-5}$ use of adjunctive solvents and/or ultrasonics, ${ }^{6-8}$ and nickel-titanium (NiTi) rotary systems. ${ }^{3,6,9,10}$ In addition, it is recommended to use a solvent to facilitate the removal of gutta-percha by softening it. ${ }^{2}$ Chloroform is a widely used solvent, because of its effective action in dissolving sealing material. Its use has had some restrictions because of its possible carcinogenic potential. Nonetheless, chloroform is considered safe if used carefully and in a clinically controlled manner. ${ }^{11}$ Another limitation is that chloroform leaves a thin layer or a soft gutta-percha film. ${ }^{12}$

Recently a new technique using reciprocating motion was proposed for endodontic treatment. ${ }^{13}$ This method relieves stress on the instrument by special counter-clockwise (cutting action) and clockwise (release of the instrument) movements and, therefore, extends the durability of a NiTi rotary instrument and increase its resistance to fatigue compared to continuous rotation motion. ${ }^{14,15}$ Even though there is accumulating evidence of safety and shaping effectiveness of the reciprocating motion, ${ }^{13-16}$ knowledge of the potential benefits of using this system in retreatment cases is still lacking. ${ }^{17-19}$ Nevertheless, there is no agreement about which methods should be used for root canal filling removal using reciprocating motion.

The aim of this study was to evaluate the efficacy of Re- ciproc system, with or without solvent for endodontic filling removal from oval shaped root canals. The time required for gutta-percha removal and the instrument fracture were also evaluated. The null hypothesis tested was that there was no significant difference in the efficacy of the Reciproc system regardless of the use of gutta-percha solvent.

\section{Sample Selection}

\section{Material and Methods}

This study was approved by the Ethics Committee of the Piracicaba Dental School, State University of Campinas UNICAMP, Piracicaba, SP, Brazil. Forty maxillary premolars extracted with a single oval-shaped canal were selected from a random collection of teeth freshly extracted due to periodontal or prosthetic reasons. Bucco-lingual and mesio-distal radiographic projections were used to select teeth with single oval-shaped canal, that is, a long:short diameter ratio of the canal $\geq 2.5: 1$ at $5 \mathrm{~mm}$ from the apex..$^{20}$ The teeth with straight roots, mature root apex and similar anatomical characteristics were selected for this study. After access cavity, the canal patency was established with a size 10 K-type file (Dentsply Maillefer, Ballaigues, Switzerland). Root canals that were patent to greater than International Standards Organization (ISO) size 20 and/or with curvature $>15$ degrees were discarded.

\section{Root Canal Preparation and Filling}

A size $15 \mathrm{~K}$-file (Dentsply Maillefer) was placed into the canal until it was visible at the apical foramen. The working length was established $1 \mathrm{~mm}$ short of this length. Root 
canals were prepared using the Protaper Universal instruments (Dentsply Maillefer) used according to manufacturer's instructions. The following sequence was used: SX file [1/2 of the working length (WL)], S1 file ( $2 / 3$ of the WL), S2 file ( $2 / 3$ of the WL), and F1, F2, and F3 files (full WL). Root canals were irrigated with $2 \mathrm{~mL}$ of $5.25 \%$ sodium hypochlorite $(\mathrm{NaOCl})$ at each change of file. Then, the smear layer was removed with $5 \mathrm{~mL}$ of $17 \%$ ethylenediaminetetraacetic acid (EDTA) for $3 \mathrm{~min}$ and flushed with $10 \mathrm{~mL}$ of distilled water.

Before the obturation, root canals were dried with paper points and filled with a .06 taper gutta-percha point size 35 coated with AH Plus sealer (Dentsply De Trey, Konstanz, Germany) using the continuous wave of condensation technique (System B; Analytic Technology, Redmond, WA, USA). The access openings were sealed with a temporary filling material (Coltosol F, Còltene/Whaledent AG, Alstatten, Switzerland). Teeth were radiographed at different angles to verify the quality of filling procedure and the presence of bubbles. Samples displaying radiographic void inside the gutta-percha were discarded and replaced. The samples were then placed in $100 \%$ humidity for 14 days to ensure complete setting of the sealer. After this period, all samples were pair-matched. Pair selection was based on visual and radiographic similarity in shape and working length size. One tooth from each pair was randomly distributed (http://www.random.org) into 2 experimental groups $(n=20)$.

\section{Root Canal Retreatment}

Each 20-specimen group was treated according to the following gutta-percha removal techniques:

- Reciproc group (RS) - Root canal filling material was removed using a R40 Reciproc (VDW, Munchen, Germany) file having a size 40 at the tip and taper of .06 over the first $3 \mathrm{~mm}$, used in a reciprocating, slow in-and-out pecking motion with an amplitude of approximately $3 \mathrm{~mm}$ and brushing action with lateral pressing movements. After three pecking motions, the instrument was removed from the canal and cleaned with sterile gauze. The instruments were used with a VDW electric motor using Reciproc motion program, according to the manufacturer's instructions.

- Reciproc with Chloroform group (RS+C) - Before the instrument introduction, chloroform $(0.5 \mathrm{~mL})$ was placed in the pulp chamber to soften the gutta-percha for 30 seconds. This time was not counted as instrumentation time. Solvent was delivered all at once. Then, the R40 instrument was introduced and used as described for RS group.

For both groups, root canals were irrigated with 5.25\% $\mathrm{NaOCl}$ after each removal of the file. Retreatment was judged to be complete when no gutta-percha or sealer was detected on the file surfaces or inside the root canal or dentinal walls after evaluation under dental operating microscope (DFV, Valença, RJ, Brazil). After retreatment, smear layer was removed with $5 \mathrm{~mL}$ of $17 \%$ EDTA for 3 minutes and flushed with $10 \mathrm{~mL}$ of distilled water. Supported by previous study, ${ }^{21}$ Reciproc files were used safety in 2 samples and discarded after instrumentation.

\section{Gutta-percha Removal Assessment}

After the filling removal, samples were grooved longitudinally with a low-speed saw under water cooling and split into halves with a chisel. Halves were viewed through a stereomicroscope (Zeiss Stemi SV6, Carl Zeiss, Jena, Germany). Pictures were taken with a camera (Axio Cam, Carl Zeiss) at a magnification of 10x. The images were transferred to image analysis software (UTHSCSA Image Tool 3.0, San Antonio, TX, USA) to measure the areas of residual filling material and root canal walls. One blinded observer was used to assess remnants of filling materials. Areas containing remaining sealing material (gutta-percha and sealer) in each part of the root canal were identified, analyzed and measured. The amount of remaining filling materials and total root canal area observed from the three thirds were added. The calculation of area percentages of residual filling material were obtained by dividing the area with residual material by the corresponding root canal area and multiplying by 100 . The averages of the values obtained from each half were used.

\section{Time Required for Gutta-percha Removal}

The total time needed to complete the procedure was recorded for each sample. Time measurements were performed by the same operator. Time included irrigation protocol during the retreatment.

\section{Procedural Errors}

The number and type of fractured and deformed instruments were visually analyzed using loups with $3 x$ magnification.

\section{Statistical Analysis}

Data were subjected to Kolmogorov Smirnov and Student's t-test with the significance set at the $95 \%$ confidence level.

\section{Results}

All samples had filling material remnants in the canal, except 2, in the RS group. Table 1 shows the averages of the area of residual filling material to the area of root canals after instrumentation for each group. Analysis of the total area revealed no statistical differences between the two groups $(P>05)$. Both of them also showed similar results in all tested thirds, without any statistical differences $(P>.05)$ 
Table 1. Mean \pm SD of the area of residual filling material by canal region after instrumentation, as well as statistical significance*

\begin{tabular}{c|c|c|c|c}
\hline Group & Cervical & Middle & Apical & Total \\
\hline \multirow{2}{*}{ RS } & $2.5 \%$ & $4.2 \%$ & $14.7 \%$ & $6.2 \%$ \\
& $(1.9)^{\mathrm{Aa}}$ & $(2.2)^{\mathrm{Aa}}$ & $(13.1)^{\mathrm{Ab}}$ & $(4.9)^{\mathrm{A}}$ \\
\hline \multirow{2}{*}{$\mathrm{RS}+\mathrm{C}$} & $3.1 \%$ & $7.4 \%$ & $17.4 \%$ & $8.7 \%$ \\
& $(2.4)^{\mathrm{Aa}}$ & $(4.3 \%)^{\mathrm{Aa}}$ & $(11.3)^{\mathrm{Ab}}$ & $(5.4)^{\mathrm{A}}$ \\
\hline
\end{tabular}

*For each column, values followed by same capital letters are statistically similar $(P>.05)$. For each row different lowercases represent significant differences between the different root canal thirds in the same group $(P>.05)$.

\section{A}

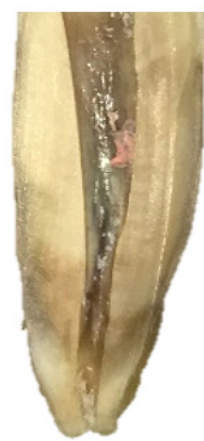

B

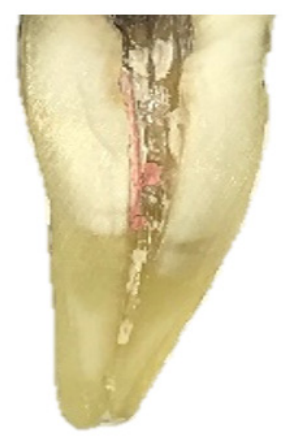

Figure 1. Representative slices of (A) RS and (B) RS + C groups

Regarding the mean time of retreatment, the use of Reciproc files with no solvent was significantly faster than with the use of solvent $(P<0.05)$ (Table 2$)$. For both groups, no separated and no permanently deformed files were noted.

Table 2. Mean \pm SD of the time necessary for retreatment and number (percentage) of cases that had file fracture recorded for the different groups, as well as statistical significance*

\begin{tabular}{c|c|c}
\hline Group & Time (s) & Fracture (\%) \\
\hline RS & $172.3 \pm 41.3^{\mathrm{A}}$ & $0(0 \%)$ \\
\hline RS + C & $245.2 \pm 62.9^{\mathrm{B}}$ & $0(0 \%)$ \\
\hline
\end{tabular}

*Different capital letters represent significant differences between the tested groups $(P>.05)$.

\section{Discussion}

Conventional endodontic retreatment is the treatment of choice for the endodontic failures cases. ${ }^{22-24}$ The removal of the filling material as much as possible is essential to obtain the elimination of remains of necrotic tissues or bacteria that may be causing inflammation and periapical lesions. ${ }^{12}$ However, the complete removal of root filling material from root canal irregularities, such as oval extensions, isthmus and apical deltas, represents a challenge due to the anatomical complexity and consequently inaccessibility of instruments and irrigants. ${ }^{5}$

Residual root filling obturation materials on root canal can block irrigating solutions and intracanal medicaments from contacting the surface of the underlying dentin, preventing disinfection. ${ }^{25}$ The permanency of bacteria, or their products and infected pulp tissue remnants which may be hidden beneath the root canal filling material may reduce the cleaning and disinfecting capacities of the mechanical and chemical procedures. ${ }^{26}$ Hence, the unremoved organic content are major causes of maintenance the persistent periapical infection. ${ }^{27,28}$

Conventionally, removal of gutta-percha using hand-files with or without solvent ${ }^{29}$ can be a tedious and time-consuming process, especially when the root canal filling material is well condensed. ${ }^{12}$ A recent study showed that reciprocating technique was effective in endodontic retreatment, requiring less time than rotary and hand files. ${ }^{19,27,3}$ The present study was designed to evaluate the ability of Reciproc System to remove root canal filling material from the canal with or without solvent. Despite the undesirable properties of chloroform, such as the local toxicity in contact with periradicular tissues, hepatotoxicity and nephrotoxicity, ${ }^{31,32}$ it is the most efficient gutta-percha solvent and one of the most used in clinics. ${ }^{31-33}$ Based on these informations, chloroform was the chosen solvent for this study.

Neither Reciproc System with nor Reciproc System without solvent rendered the canals free of root filling material. Indeed, both retreatment methods left substantial amounts of material on the canal walls. This could be attributed to the internal anatomy of mandibular premolars, which have some recesses that hinder complete removal of filling material, regardless of the kind of file, motion or even the gutta-percha solvent used. These aspects increase the difficulty of the root canal cleaning and shaping that may require additional procedures in root canal retreatment as quoted in previous studies. ${ }^{5,34,35}$ The oval-shaped root canals were selected for this evaluation to provide additional challenges in endodontic retreatment due to their noncircular anatomy. ${ }^{36}$

Several methods have been applied to evaluate the quality of root filling removal after various endodontic retreatment techniques. ${ }^{37-39}$ Previous studies showed that SEM can provide direct topographical and morphological data on the root filling materials. ${ }^{40}$ Recently, Micro-CT can supply 3D and accurate quantitatively and qualitatively data of the root canal and its content, representing a reproducible and noninvasive method that allows a detailed assessment of morphological characteristics of the object under analysis ${ }^{36,41,42}$ and reduces potential operator bias in the interpretation of the results. ${ }^{43}$

Nevertheless, the present study used stereomicroscope magnification to assess the effectiveness of a solvent in endodontic retreatment associated to reciprocating instrumentation. Although this is a recognized methodology, a disadvantage of the method applied is that only a small portion of the root canal can be evaluated and the principal limitation of the method is that part of the specimen may be lost in the sectioning procedure. ${ }^{2,39,44}$ Compared to the methods of 
analysis that use sectioning, Micro-CT maintains the integrity of the sample that can be reused. ${ }^{38,45,46}$

Previous studies showed a shorter retreatment time when files were used associated with solvent. ${ }^{6,12}$ Conversely, the use of Reciproc System without solvent speeded up retreatment time in this study. Similar results were also reported by Takahashi et al., ${ }^{3}$ using ProTaper Universal Retreatment Files (URF). They showed that while Protaper URF without solvent completed the procedure within $5.7 \mathrm{~min}$, their use with chloroform took $8.8 \mathrm{~min}$ for complete removal of the old root canal filling.

Solvents should be used only in cases of extreme difficulty in removing the gutta-percha, as they create a thin layer of softened gutta-percha that adheres to the root canal wall.
Such a layer can be easily forced into the complex root canal anatomy (isthmuses, cul de sacs, lateral canals and irregularities) that are not touched by the instruments. ${ }^{12,47}$ Once created, accentuates the challenges of filling removal and requires more time to be removed. The use of an operating microscope can improve visualization of this layer and aid in its removal.

\section{Conclusion}

Taken together, our results demonstrated that Reciproc System used without solvent required less time to remove the same amount of root filling material than Reciproc System with solvent. However, regardless of solvent use, the same cleaning quality was obtained.

\section{References}

1. Mounce R. Endodontic retreatment possiblities: evaluation, limitations and considerations. Compend Contin Educ Dent. 2004;25:364-8.

2. Tasdemir T, Yildirim T, Celik D. Comparative study of removal of current endodontic fillings. J Endod. 2008;34:326-9.

3. Takahashi CM, Cunha RS, de Martin AS, Fontana CE, Silveira CFM, da Silveira Bueno CE. In vitro evaluation of the effectiveness of ProTaper Universal rotary retreatment system for gutta-percha removal with or without a solvent. J Endod. 2009;35:1580-3.

4. Bramante CM, Fidelis NS, Assumpção TS, Bernardineli N, Garcia RB, Bramante AS, et al. Heat release, time required, and cleaning ability of Mtwo R and ProTaper Universal retreatment systems in the removal of filling material. J Endod. 2010;36:1870-3.

5. Zmener O, Pameijer CH, Banegas G. Retreatment efficacy of hand versus automated instrumentation in oval-shaped root canals: an ex vivo study. Int Endod J. 2006;39:521-6.

6. Giuliani V, Cocchetti R, Pagavino G. Efficacy of ProTaper Universal retreatment files in removing filling materials during root canal retreatment. J Endod. 2008;34:1381-4.

7. Unal GC, Kaya BU, Tac, AG, Keçeci AD. A comparison of the efficacy of conventional and new retreatment instruments to remove gutta-percha in curved root canals: an ex vivo study. Int Endod J. 2009;42:344-50.

8. Bernardes RA, Duarte MA, Vivan RR, Alcalde MP, Vasconcelos BC, Bramante $\mathrm{CM}$. Comparison of three retreatment techniques with ultrasonic activation in flattened canals using micro-computed tomography and scanning electron microscopy. Int Endod J. 2016;49:890-7

9. Baratto-Filho F, Ferreira EL, Fariniuk LF. Efficiency of the 0.04 taper ProFile during the re-treatment of guttapercha- filled root canals. Int Endod J. 2002;35:651-4.

10. Gergi R, Sabbagh C. Effectiveness of two nickel-titanium rotary instruments and a hand file for removing gutta-percha in severely curved root canals during retreatment: An ex vivo study. Int Endod J. 2007;40:532-7.

11. McDonald MN, Vire DE. Chloroform in the endodontic operatory. J Endod. 1992;18:301-3.

12. Sae-Lim V, Rajamanickam I, Lim BK, Lee HL. Effectiveness of Profile .04 taper rotary instruments in endodontic retreatment. J Endod. 2000;26:100-4.

13. Yared G. Canal preparation using only one Ni-Ti rotary instrument: preliminary observations. Int Endod J. 2008;41:339-44.

14. De-Deus G, Brandão MC, Barino B, Di Giorgi K, Fidel RA, Luna AS. Assessment of apically extruded debris produced by the single-file ProTaper F2 technique under reciprocating movement. Oral Surg Oral Med Oral Pathol Oral Radiol Endod. 2010;110:390-4.

15. Varela-Patiño P, Ibañez-Párraga A, Rivas-Mundiña B, Cantatore G, Otero XL, Martin-Biedma B. Alternating versus continuous rotation: a comparative study of the effect on instrument life. J Endod. 2010;36:157-9.

16. Arias A, Perez-Higueras JJ, de la Macorra JC. Differences in cyclic fatigue resistance at apical and coronal levels of Reciproc and WaveOne new files. J Endod. 2012;38:1244-8.

17. Comparin D, Moreira EJL, Souza EM, De-Deus G, Arias A, Silva EJNL. Post- operative pain after endodontic retreatment using rotary or reciprocating instruments: a randomized clinical trial. J Endod. 2017;43:1084-8.

18. Silva EJNL, Ferreira VM, Silva CC, Herrera DR, De-Deus G, Gomes BP. Influence of apical enlargement and complementary canal preparation with the Self-Adjusting File on endotoxin reduction in retreatment cases. Int Endod J. 2017;50:646-51.

19. Silva EJ, Brito ME, Ferreira VD, Belladonna FG, Neves AA, Senna PM, De-Deus G. Cytotoxic effects of the debris apically extruded during three different retreatment procedures. J Oral Sci. 2016;58:211-7.

20. De-Deus G, Reis C, Beznos D, de Abranches AM, Coutinho-Filho T, Paciornik S. Limited ability of three commonly used thermoplasticized gutta-percha techniques in filling oval-shaped canals. J Endod 2008;34:140-5.

21. Bueno CSP, Oliveira DP, Pelegrine RA, Fontana CE, Rocha DGP, Bueno CEDS. Fracture Incidence of WaveOne and Reciproc Files during Root Canal Preparation of up to 3 Posterior Teeth: A Prospective Clinical Study. J Endod. 2017;43:705-8.

22. Moiseiwitsch JR, Trope M. Nonsurgical root canal therapy treatment with apparent indications for root-end surgery. Oral Surg Oral Med Oral Pathol Oral Radiol Endod. 1998;86:335-40.

23. Del Fabbro M, Taschieri S. A systematic review on the outcome of surgical vs non-surgical procedure for the retreatment of periapical lesions. Minerva Stomatol. 2007;56:621-32.

24. Kvist T. Endodontic retreatment. Aspects of decision making and clinical outcome. Swed Dent J Suppl. 2001;144:1-57

25. Rôças IN, Siqueira JF Jr. Characterization of microbiota of root canal-treated teeth with posttreatment disease. J Clin Microbiol. 2012;50:1721-4.

26. Fabricius L, Dahle'n G, Sundqvist G, Happonen RP, Möller AJ. Influence of residual bacteria on periapical tissue healing after chemomechanical treatment and root filling of experimentally infected monkey teeth. Eur J Oral Sci. 2006;114:278-85.

27. Silva EJ, Orlowsky NB, Herrera DR, Machado R, Krebs RL, Coutinho-Filho Tde S. Effectiveness of rotatory and reciprocating movements in root canal filling material removal. Braz Oral Res. 2015;29:1-6.

28. Ricucci D, Siqueira JF Jr, Bate AL, Pitt Ford TR. Histologic investigation of root canaltreated teeth with apical periodontitis: a retrospective study from twenty-four patients. J Endod. 2009;35:493-502.

29. Hulsmann M, Stotz S. Efficiency, cleaning ability and safety of different devices for gutta-percha in root canal retreatment. Int Endod J. 1997;30:227-33.

30. Zuolo AS, Zuolo ML, da Silveira Bueno CE, Chu R, Cunha RS. Evaluation of the efficacy of TRUShape and Reciproc file systems in the removal of root filling material: an ex vivo micro-computed tomographic study. J Endod. 2016;42:315-9. 31. Wennberg A, Orstavik D. Evaluation of alternatives to chloroform in endodontic practice. Endod Dent Traumatol. 1989;5:234-7.

32. Zakariasen KL, Brayton SM, Collinson DM. Efficient and effective root canal retreatment without chloroform. J Can Dent Assoc. 1990;56:509-12.

33. Wilcox LR. Endodontic retreatment with halothane versus chloroform solvent. J Endod. 1995;21:305-7.

34. Ma J, Al-Ashaw AJ, Shen Y, Gao Y, Yang Y, Zhang C, et al. Efficacy of ProTaper 
Universal Rotary Retreatment system for gutta-percha removal from oval root canals: a micro-computed tomography study. J Endod. 2012;38:1516-20.

35. Rechenberg DK, Paque F. Impact of cross-sectional root canal shape on filled canal volume and remaining root filling material after retreatment. Int Endod J. 2013;46:547-55.

36. Versiani MA, Pecora JD, de Sousa-Neto MD. Flat-oval root canal preparation with self-adjusting file instrument: a micro-computed tomography study. J Endod. 2011;37:1002-7.

37. Mello Junior JE, Cunha RS, Bueno CE, Zuolo ML. Retreatment efficacy of guttapercha removal using a clinical microscope and ultrasonic instruments: part I - an ex vivo study. Oral Surg Oral Med Oral Pathol Oral Radiol Endod. 2009; 108:59-62.

38. Zuolo AS, Mello JE, Cunha RS, Zuolo ML, Bueno CE. Efficacy of reciprocating and rotary techniques for removing filling material during root canal retreatment. Int Endod J. 2013;46:947-53.

39. Saad AY, Al-Hadlaq SM, Al-Katheeri NH. Efficacy of two rotary NiTi instrunents in the removal of gutta-percha during root canal retreatment. J Endod. 2007;3:38-41.

40. Upadhyay V, Upadhyay M, Panday RK, Chturvedi TP, Bajpai U. A SEM evaluation of dentinal adaptation of root canal obturation with GuttaFlow and conventional obturating material. Indian J Dent Res. 2011;22:881.
41. Asheibi F, Qualtrough AJ, Mellor A, Withers PJ, Lowe T. Micro-CT evaluation of the effectiveness of the combined use of rotary and hand instrumentation in removal of Resilon. Dent Mater J. 2014;33:1-6.

42. Paque F, Peters OA. Micro-computed tomography evaluation of the preparation of long oval root canals in mandibular molars with the self-adjusting file. J Endod. 2011;37:517-21.

43. Solomonov M, Paque F, Kaya S, Adigüzel O, Kfir A, Yiğit-Özer S. Self-adjusting files in retreatment: a highresolution micro-computed tomography study. J Endod. 2012;38:1283-7.

44. Kfir A, Tsesis I, Yakirevich E, Matalon S, Abramovitz I. The efficacy of five retreatment techniques: microscopic vs. radiographic evaluation. Int Endod J. 2012;45:35-41.

45. Rios MA, Villela AM, Cunha RS, Velasco RC, De Martin AS, Kato AS, et al. Efficacy of 2 reciprocating systems compared with a rotary retreatment system for gutta-percha removal. J Endod. 2014;40:543-6.

46. Ozy € €urek T, Demiry€urek EO. Efficacy of different nickel-titanium instruments in $€$ removing gutta-percha during root canal retreatment. J Endod. 2016;42:646-9.

47. Gu LS, Ling JQ, Wei X, Huang XY. Efficacy of ProTaper Universal rotary retreatment for gutta-percha removal from root canals. Int Endod J. 2008;41:288-95.

\section{Mini Curriculum and Author's Contribution}

1. Nancy Kudsi Carvalho - DDS, MSc. Contribution: bibliographical research, experimental procedures, manuscript writing.

2. Gustavo Ribeiro Alvares - DDS, MSc, PhD. Contribution: bibliographical research, experimental procedures, manuscript writing.

3. Luciana Moura Sassone - DDS, MSc, PhD. Contribution: manuscript writing, manuscript review, image editing.

4. Renato Lies Krebs - DDS, MSc, PhD. Contribution: manuscript writing, manuscript review.

5. Tauby de Souza Coutinho-Filho - DDS, MSc, PhD. Contribution: manuscript writing, manuscript review.

6. Emmanuel João Nogueira Leal da Silva - DDS, MSc, PhD. Contribution: manuscript review, statistical analysis, image editing, work supervisor and paper submission.

Submitted: 08/08/2017 / Accepted for publication: 08/27/2017

\section{Corresponding Author}

Emmanuel João Nogueira Leal Silva

E-mail: nogueiraemmanuel@hotmail.com 